\title{
Short-lived delirium caused by single-shot corticosteroids
}

\author{
Johannes Prottengeier, Stefan Leucht, Torsten Birkholz
}

\begin{abstract}
Introduction: Corticosteroids have many indications in medicine. Side effects are not uncommon, but psychiatric disorders in response to a single dose treatment are very rare. Case Report: We report of a previously mentally healthy 43-year-old female who received a single dose of $4 \mathrm{mg}$ intramuscular dexamethasone and subsequently developed a short-lived delirium within hours of administration. Conclusion: Steroid delirium and psychosis are well known in literature, but reports on such an immediate adverse reaction are rare. The underlying biochemical mechanisms are unknown, but prognosis upon discontinuation of steroid intake is generally favorable.
\end{abstract}

Keywords: Steroids, Delirium, Single-shot corticosteroids, Adverse drug reaction

\section{How to cite this article}

Prottengeier J, Leucht S, Birkholz T. Short-lived delirium caused by single-shot corticosteroids. International Journal of Case Reports and Images 2014;5(4):270-272.

Johannes Prottengeier ${ }^{1}$, Stefan Leucht ${ }^{2}$, Torsten Birkholz ${ }^{3}$ Affiliations: ${ }^{1} \mathrm{MD}$, Resident, Department of Anesthesia, University Hospital, Erlangen, Germany; ${ }^{2} \mathrm{MD}$, Professor of Psychiatry, Deputy Head, Department of Psychiatry, TechnicalUniversity of Munich, Germany; ${ }^{3} \mathrm{MD}$, Assistant Professor of Anesthesiology, Consultant, Department of Anesthesia, University Hospital, Erlangen, Germany Corresponding Author: Johannes Joachim Prottengeier, MD, Department of Anesthesia, Erlangen University Hospital, Krankenhausstraße 12, D-91054 Erlangen, Germany; Ph: +49-9131-85-42332; Fax: +49-9131-85-36147; Email: johannes.prottengeier@kfa.imed.uni-erlangen.de

Received: 22 August 2013

Accepted: 18 September 2013

Published: 01 April 2014 doi: 10.5348/ijcri-201455-CR-10366

\section{INTRODUCTION}

Since the discovery of cortisone (Edward Kendall being awarded the Nobel Prize for Medicine for this achievement in 1950) steroids have found multiple indications in modern drug therapy. Besides their use in immunologic and allergic disorders and many more, they have also proven themselves beneficiary as co-analgesics in chronic pain disorders [1]. Adverse drug reactions to corticosteroids are plentiful and psychiatric side effects are well-known with long-term administration of high doses [2-4]. We report a rare case of short-lived delirium caused by a single and low-dose application of dexamethasone intended as a co-analgetic in a previously mentally healthy patient. Secondly, we will illustrate the clinical characteristics, risk factors, treatment options and proposed mechanisms of disease of steroid induced delirium and psychosis.

\section{CASE REPORT}

A female in her mid-forties consulted her orthopedist for the aggravation of chronic severe back pain first diagnosed years before. The physical examination showed again muscle tension and pain in both cervical and lumbar region. No neurological deficits were detected. No other complaints were stated and the patient made a mentally unimpaired impression. The orthopedist injected $4 \mathrm{mg}$ of dexamethasone intramuscular and sent the patient home in a stable condition. A few hours later, she called her general practitioner complaining of general discomfort, unrest, anxiety and tightness in her throat. He paid a home visit and suspected anaphylaxis, immediately injected clemastine and ranitidine, and alerted our emergency medical service.

At our initial assessment patient history revealed no pre-existing allergies. Her medication consisted of transdermal fentanyl $(50 \mu \mathrm{g} / \mathrm{hr})$ and metamizole (on 
demand, up to $500 \mathrm{mg}$ q.i.d.). There were no detours from her daily routine other than the visit to the orthopedist, no extra medication, no illicit or recreational drugs. Physical examination showed no signs of allergy: oral mucosa appeared normal, there was no bronchoconstriction, flush or pruritus. A basic neurological examination found no abnormalities. Except a noticeable agitation, all movements were precise and thinking appeared to be coherent, as she could explain the situation rationally to her children just coming home from school.

There was no sound explanation for the symptoms and anaphylaxis seemed unlikely: the patient was admitted to the emergency room. Within few minutes of the transfer to the hospital, she developed severe anxiety and confusion. She experienced visual and acoustical hallucinations of her children and husband, tried to climb off the stretcher while the ambulance was still driving and had to be restrained physically. All efforts of talking her down were futile, and there was practically no clinical response to $5 \mathrm{mg}$ of midazolam intravenously.

Just after arrival in the emergency room, the patient had developed a deliriant state. She experienced further hallucinations of her family, tried to undress herself and was totally unresponsive to questions and instructions.

The attending physician in the emergency room thought of akathisia because of a noticeable motoric unrest as a potential diagnosis, but there was no pathognomonic pattern of movement and probatory injection of $5 \mathrm{mg}$ biperiden intravenous had no clinical effect. Intravenously administered, repeated doses of diazepam made the patient markedly calmer and responsive to orders, but with persisting formal symptoms of the delirium. The diagnosis of this probably steroid-induced delirium was confirmed by the consulting neurologist. In the meantime, the symptoms had resolved partially, and he advised against any further intervention. It took another eight to twelve hours before the symptoms finally resolved. The patient then had an uneventful clinical course and was discharged home the next morning with no residual symptoms.

Further history of the patient showed that she never had experienced psychotic symptoms before. Several followups with neurologist and psychiatrist, the latest 6 months after the initial incident, revealed no further abnormalities or formal diagnoses besides the known chronic pain disorder. Interestingly, she could recollect the events quite in detail, but had no explanation for her behavior.

\section{DISCUSSION}

In this case, the most likely explanation for such a extremely short-term but serious mental alteration of the patient is the single low dose of steroids $(4 \mathrm{mg}$ dexamethason).

Adverse psychiatric reactions to steroids have been known since Harvey Cushing first formulated 'Dyspituitarism' in 1932 and this case again reminds of the great variety in their clinical manifestations [2]. Most commonly are mood disorders such as mania or depression [3]. Furthermore, there have been reports of insomnia, agitation, aggressive behavior or cognitive disorders up to full dementia [4]. And with relevance to our case there have been many reports of delirium and psychosis, whereas literature does not clearly differentiate between the two entities in connection with steroids [5]. The development of steroid-induced delirium and psychosis is generally assumed to be dose-dependent and to be a function of time. Some studies found prevalence of up to $18.4 \%$ in patients receiving more than $80 \mathrm{mg} / \mathrm{die}$ of prednisone [6]. It usually takes 7-14 days of treatment before the onset of symptoms [7]. A rapid onset of disease as experienced with our patient has not been reported before. In this case, there are no obvious confounding factors. Ranitidine has been reported to cause confusion, even delirium [8]. But the timeline of events indicates otherwise: The onset of symptoms was well before ranitidine was given.

The immediate treatment of steroid induced delirium and psychosis could consist of antipsychotics and additional sedatives [9]. Prognosis of steroid induced mental disorders is generally favorable. The abstinence from the drug itself usually results into full clinical recovery [9]. When steroids are an essential part of a therapeutic regime and cannot be stopped or reduced, there have been reports that steroid psychosis can be prevented by prophylactic lithium, gabapentin or neuroleptics such as chlorpromazine [10].

Neither co-morbidities nor even previous steroid induced delirium or psychosis themselves are predictors for their occurrence [11]. The underlying biochemical mechanisms are unclear. Steroids interfere with glutamate levels and can cause hippocampal dysfunction [12]. How altered hippocampal glutamate levels could result in distinct psychiatric disorders has not been explained yet. After all, the vast majority of steroid treatments do not cause any mental alteration.

\section{CONCLUSION}

Psychiatric disorders following treatment with corticosteroids are well known, but such an immediate adverse reaction to a single dose of $4 \mathrm{mg}$ of dexamethasone has not been reported before. Bridging with mild sedatives allowed for a spontaneous remission of symptoms. The underlying biochemical mechanisms of this adverse drug reaction however are still unclear.

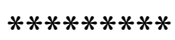

\section{Author Contributions}

Johannes Prottengeier - Conception and design, Acquisition of data, Analysis and interpretation of data, Drafting the article, Critical revision of the article, Final approval of the version to be published 
Stefan Leucht - Analysis and interpretation of data, Critical revision of the article, Final approval of the version to be published

TorstenBirkholz - Analysis and interpretation of data, Critical revision of the article, Final approval of the version to be published

\section{Guarantor}

The corresponding author is the guarantor of submission.

\section{Conflict of Interest}

Authors declare no conflict of interest.

\section{Copyright}

(C) Johannes Prottengeier et al. 2014; This article is distributed under the terms of Creative Commons attribution 3.0 License which permits unrestricted use, distribution and reproduction in any means provided the original authors and original publisher are properly credited. (Please see www.ijcasereportsandimages.com/ copyright-policy.php for more information.)

\section{REFERENCES}

1. Miaskowski C, Bair M, Chou R, et al. Principles of Analgesic Use in the Treatment of Acute Pain and Cancer Pain, 6ed. Chicago (USA): American Pain Society; 2008.

2. Cushing H. Harvey Lectures-Dyspituitarism. Bull. Johns Hopkins Hosp 1932;50:137.
3. Brown ES. Effects of glucocorticoids on mood, memory, and the hippocampus. Treatment and preventive therapy. Ann N Y Acad Sci 2009;1179:4155.

4. Wolkowitz OM, Burke H, Epel ES, Reus VI. Glucocorticoids. Mood, memory, and mechanisms. Ann N Y Acad Sci 2009;1179:19-40.

5. Warrington TP, Bostwick JM. Psychiatric adverse effects of corticosteroids. Mayo Clin Proc 2006;81(10):1361-7.

6. Boston Collaborative Drug Surveillance Program. Drug-induced convulsions. Report from the Boston Collaborative Drug Surveillance Program. Lancet 1972;2(7779):677-9.

7. Wada K, Yamada N, Sato T, et al. Corticosteroidinduced psychotic and mood disorders: Diagnosis defined by DSM-IV and clinical pictures. Psychosomatics 2001;42(6):461-6.

8. Picotte-Prillmayer D, DiMaggio JR, Baile WF. H2 blocker delirium. Psychosomatics 1995;36(1):74-7.

9. Wada K, Yamada N, Suzuki H, Lee Y, Kuroda S. Recurrent cases of corticosteroid-induced mood disorder: clinical characteristics and treatment. J Clin Psychiatry 2000;61(4):261-7.

10. Dubovsky AN, Arvikar S, Stern TA, Axelrod L. The neuropsychiatric complications of glucocorticoid use: steroid psychosis revisited. Psychosomatics 2012;53(2):103-15.

11. Patten SB, Neutel CI. Corticosteroid-induced adverse psychiatric effects: Incidence, diagnosis and management. Drug Saf 2000;22(2):111-22.

12. Mora F, Segovia G, Del Arco A, de Blas M, Garrido P. Stress, neurotransmitters, corticosterone and bodybrain integration. Brain Res 2012;1476:71-85.
Access full text article on other devices

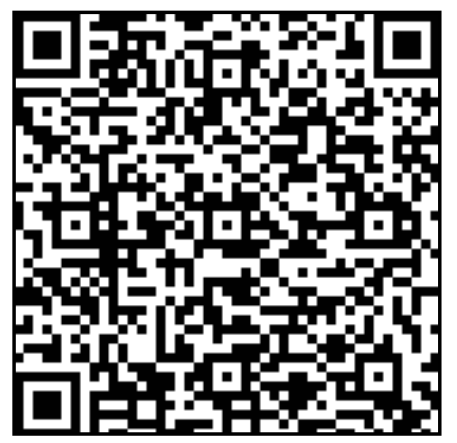

Access PDF of article on other devices

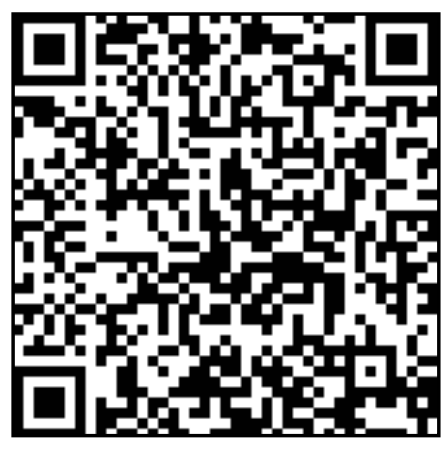

